\title{
Clinical Study \\ Relationship between Nutrition Knowledge and Physical Fitness in Semiprofessional Soccer Players
}

\author{
P. T. Nikolaidis ${ }^{1,2}$ and E. Theodoropoulou ${ }^{3}$ \\ ${ }^{1}$ Department of Physical and Cultural Education, Hellenic Army Academy, 16672 Athens, Greece \\ ${ }^{2}$ Exercise Physiology Laboratory, 18450 Nikaia, Greece \\ ${ }^{3}$ Faculty of Physical Education and Sport, University of Athens, 17237 Athens, Greece \\ Correspondence should be addressed to P. T. Nikolaidis; pademil@hotmail.com
}

Received 20 January 2014; Revised 3 July 2014; Accepted 11 July 2014; Published 21 July 2014

Academic Editor: Lawrence M. Lewis

Copyright (c) 2014 P. T. Nikolaidis and E. Theodoropoulou. This is an open access article distributed under the Creative Commons Attribution License, which permits unrestricted use, distribution, and reproduction in any medium, provided the original work is properly cited.

\begin{abstract}
Whereas nutrition has a crucial role on sport performance, it is not clear to what extent nutrition knowledge is associated with physical fitness. The aim of this study was to examine the current level of nutrition knowledge of soccer players and whether this level is associated with physical fitness. Soccer players $(n=185$, aged $21.3 \pm 4.9 \mathrm{yr}$, weight $72.3 \pm 8.4 \mathrm{~kg}$, and height $177.5 \pm 6.4 \mathrm{~cm})$ performed a battery of physical fitness tests (sit-and-reach test, SAR; physical working capacity in heart rate 170, PWC170; and Wingate anaerobic test, WAnT) and completed an 11-item nutrition knowledge questionnaire (NKQ). Low to moderate Pearson correlations $(0.15<r<0.34, p<0.05)$ of NKQ with age, weight, height, fat free mass (FFM), SAR, peak power, and mean power of WAnT were observed. Soccer players with high score in NKQ were older $(4.4 \mathrm{yr}(2.2 ; 6.6)$, mean difference $(95 \%$ confidence intervals $))$ and heavier $(4.5 \mathrm{~kg}(0.6 ; 8.3))$ with higher FFM $(4.0 \mathrm{~kg}(1.1 ; 6.8))$ and peak power $(59 \mathrm{~W}(2 ; 116))$ than their counterparts with low score. The moderate score in the NKQ suggests that soccer players should be targeted for nutrition education. Although the association between NKQ and physical fitness was low to moderate, there were indications that better nutrition knowledge might result in higher physical fitness and, consequently, soccer performance.
\end{abstract}

\section{Introduction}

Soccer is a sport taxing both aerobic and anaerobic energy transfer systems. An estimate of the energy cost of training or match-play in elite players is above $1500 \mathrm{kcal}$ [1]. The metabolism during the game relies on muscle glycogen and free-fatty acids [2]. Thus, soccer players should adopt a diet providing sufficient carbohydrates and supplying all nutrient requirements [3]. The intake of carbohydrates might range from 5 to $7 \mathrm{~g}$ per $\mathrm{kg}$ during moderate training to $10 \mathrm{~g}$ per $\mathrm{kg}$ during intense training or match-play [1]. The diet should include $55-65 \%$ carbohydrate, $12-15 \%$ protein, and less than $30 \%$ fat $[4,5]$ and should be according to soccer players' age [6]. Emphasis should also be given to have sufficient water and electrolyte levels [7].

Whereas an optimal diet is necessary to meet the abovementioned energy requirements of soccer, the existing research reveals many nutrition concerns [8-11]. For instance, in an analysis of nutrition of semiprofessional soccer players, insufficient amount of carbohydrates consumption was noticed [8]. Moreover, Garrido and colleagues compared two menu settings ("buffet-style" versus fixed "menu") and concluded that these settings did not meet the current recommendations [9]. Ruiz and colleagues examined the contribution of carbohydrates to total energy intake in soccer players of various age groups and observed that it was lower than what was recommended for athletes [10]. In another study [11], where the nutrition of adolescent soccer players was analyzed, their total energy intake was insufficient and the diet was unbalanced with great emphasis upon fatty foods. These studies highlighted the need for an optimal nutrition.

Nutrition has a crucial role on sport performance, but it is not clear to what extent nutrition knowledge is associated with physical fitness. It is reasonable to assume that better nutrition knowledge might result in better nutrition choices, which in turn might enhance various physical fitness 
components (e.g., body composition, anaerobic power, and endurance). Therefore, the aim of this study was to examine (a) the current level of nutrition knowledge of soccer players and (b) whether this level is associated with physical fitness.

\section{Methods}

2.1. Study Design and Participants. For the purpose of this study, we collected data from 185 semiprofessional soccer players $(n=185$, aged $21.3 \pm 4.9 \mathrm{yr}$, weight $72.3 \pm 8.4 \mathrm{~kg}$, and height $177.5 \pm 6.4 \mathrm{~cm}$ ), who were examined in our laboratory in the beginning of preparatory period of seasons 2011-2012 and 2013-2014. The study was approved by the local review board. All participants gave written informed consent and underwent a series of anthropometric, body composition, and physical fitness measurements (sit-and-reach test, SAR; physical working capacity in heart rate $170, \mathrm{PWC}_{170}$; and Wingate anaerobic test, WAnT), and completed an 11-item nutrition knowledge questionnaire (NKQ) [12].

\subsection{Protocols and Equipment}

(a) Anthropometry. Weight was measured with an electronic weight scale (HD-351 Tanita, Illinois, USA) in the nearest $0.1 \mathrm{~kg}$ and height with a portable stadiometer (SECA, Leicester, UK) in the nearest $1 \mathrm{~mm}$ with participants being barefoot and in minimal clothing. Body mass index was calculated as the quotient of body mass $(\mathrm{kg})$ to height squared $\left(\mathrm{m}^{2}\right)$. A caliper (Harpenden, West Sussex, UK) measured skinfolds $(0.5 \mathrm{~mm})$ and body fat percentage $(\mathrm{BF})$ was calculated from the sum of 10 skinfolds [13]. Fat free mass (FFM) was calculated as the difference between weight and the product of weight by BF.

(b) Flexibility. The sit-and-reach (SAR) protocol [14] was employed for the assessment of lower back and hamstring flexibility.

(c) Physical Working Capacity in Heart Rate $170 \mathrm{~min}^{-1}$ $\left(P W C_{170}\right)$. PWC $_{170}$ was performed according to Eurofit guidelines [15] on a cycle ergometer (828 Ergomedic, Monark, Varberg, Sweden). Seat height was adjusted to each participant's satisfaction, and toe clips with straps were used to prevent the feet from slipping off the pedals. Participants were instructed before the tests that they should pedal with steady cadence 60 revolutions per minute, which was given by both visual (ergometer's screen showing pedaling cadence) and audio means (metronome set at 60 beats per minute). This test consisted of three stages, each lasting $3 \mathrm{~min}$, against incremental braking force in order to elicit HR between 120 and 170 beats per minute $\left(\mathrm{min}^{-1}\right)$. Based on the linear relationship between $\mathrm{HR}$ and power output, $\mathrm{PWC}_{170}$ was calculated as the power corresponding to HR $170 \mathrm{~min}^{-1}$ and expressed as $\mathrm{W}$ and $\mathrm{W} \cdot \mathrm{kg}^{-1}$. HR was recorded continuously during all testing procedures by Team 2 Pro (Polar Electro Oy, Kempele, Finland).

(d) Wingate Anaerobic Test (WAnT). The WAnT was performed on a cycle ergometer (Ergomedics 874, Varberg,
Monark, Sweden). Briefly, participants were asked to pedal as fast as possible for $30 \mathrm{~s}$ against a braking force that was determined by the product of body mass in $\mathrm{kg}$ by 0.075 [16]. Peak power $\left(P_{\text {peak }}\right)$ was estimated as the average power over a 5 s period with the highest performance, which occurs usually in the first $5 \mathrm{~s}$ of the test. Mean power $\left(P_{\text {mean }}\right)$ was calculated as the average power during the $30 \mathrm{~s}$ period. Both $P_{\text {peak }}$ and $P_{\text {mean }}$ were expressed as $\mathrm{W}$ and $\mathrm{W} \cdot \mathrm{kg}^{-1}$. Fatigue index was calculated.

2.3. Statistical Analysis. Statistical analyses were performed using IBM SPSS v.20.0 (SPSS, Chicago, USA). Data were expressed as mean and standard deviations of the mean (SD) and parametric statistics were used, because significance value of Kolmogorov-Smirnov test of normality was lower than 0.001 for all variables. Pearson correlation coefficient $r$ was used to examine the relationship between NKQ and physical fitness variables. Magnitude of correlation coefficients were considered as trivial $(r<0.1)$, small $(0.1 \leq$ $r<0.3)$, moderate $(0.3 \leq r<0.5)$, large $(0.5 \leq r<0.7)$, very large $(0.7 \leq r<0.9)$, nearly perfect $(0.9 \leq r<1.0)$, and perfect $(r=1.0)$ [17]. Based on their NKQ scores, participants were classified into three groups: low (less than 5 correct answers out of 11), moderate (5 or 6 correct answers), and high nutrition knowledge (more than 6 correct answers). One-way analysis of variance (ANOVA) with a subsequent Bonferroni post-hoc test (if difference between the groups was revealed) was used to examine differences in physical and physiological characteristics among the three groups. Mean difference together with 95\% confidence intervals (CI) was calculated when the post-hoc was necessary. To interpret the effect size for statistical differences in the ANOVA we used eta square classified as small $\left(0.01<\eta^{2} \leq 0.06\right)$, medium $(0.06<$ $\left.\eta^{2} \leq 0.14\right)$, and large $\left(\eta^{2}>0.14\right)$ [17]. The level of significance was set at $\alpha=0.05$. A stepwise linear regression analysis was conducted to predict the overall NKQ score from anthropometric and physical fitness components.

\section{Results}

The answers to the NKQ can be seen in Table 1. Mean score and standard deviation of NKQ (i.e., number of correct responses) were 5.4 and 1.7. Low to moderate correlations $(0.15<r<0.34, p<0.05)$ of NKQ with age, weight, height, fat free mass (FFM), SAR, peak power, and mean power of WAnT were observed (Table 2). Soccer players with high score in NKQ were older $(4.4 \mathrm{yr}(2.2 ; 6.6)$, mean difference (95\% confidence intervals)), and heavier $(4.5 \mathrm{~kg}(0.6 ; 8.3))$ with higher FFM $(4.0 \mathrm{~kg}(1.1 ; 6.8))$ and peak power $(59 \mathrm{~W}(2$; 116)) than their counterparts with low score (Table 3$)$. NKQ score could be predicted from age by the following formula: $\mathrm{NKQ}=3.0+0.1 \times$ age, $R^{2}=0.11$.

With regards to questions on macronutrients, the majority of soccer players agreed correctly that "carbohydrates and fat are the main energy sources" and disagreed correctly that they "should consume high-fat meals 2 to 3 hours before an event" and that "eating carbohydrates makes you fat." The number of soccer players who answered correctly to 
TABLE 1: Nutrition knowledge of participants.

\begin{tabular}{|c|c|c|c|c|c|c|}
\hline & \multicolumn{2}{|c|}{ Agree } & \multicolumn{2}{|c|}{ Disagree } & \multicolumn{2}{|c|}{ Don't know } \\
\hline & No & $\%$ & No & $\%$ & No & $\%$ \\
\hline \multicolumn{7}{|l|}{ Macronutrient statements } \\
\hline Carbohydrate and fat are the main energy sources ${ }^{\mathrm{a}}$ & 116 & 62.7 & 33 & 17.8 & 36 & 19.5 \\
\hline Should not eat sweets prior to an event ${ }^{b}$ & 112 & 60.5 & 51 & 27.6 & 21 & 11.4 \\
\hline Eating carbohydrates makes you fat ${ }^{\mathrm{b}}$ & 48 & 25.9 & 94 & 50.8 & 42 & 22.7 \\
\hline Should consume high-fat meals 2 to 3 hours before an event ${ }^{b}$ & 52 & 28.1 & 107 & 57.8 & 26 & 14.1 \\
\hline Protein is the main energy source for the muscle ${ }^{b}$ & 163 & 88.1 & 7 & 3.8 & 15 & 8.1 \\
\hline Protein supplements are necessary ${ }^{\mathrm{b}}$ & 72 & 38.9 & 72 & 38.9 & 41 & 22.2 \\
\hline \multicolumn{7}{|l|}{ Hydration statements } \\
\hline Should replace fluids before, during and after an event ${ }^{\mathrm{a}}$ & 178 & 96.2 & 4 & 2.2 & 3 & 1.6 \\
\hline Sports drinks are better than water ${ }^{a}$ & 73 & 39.5 & 75 & 40.5 & 37 & 20.0 \\
\hline Should rely on thirst to ensure fluid replacement ${ }^{\mathrm{b}}$ & 22 & 11.9 & 122 & 65.9 & 40 & 21.6 \\
\hline Dehydration decreases performance ${ }^{a}$ & 162 & 87.6 & 8 & 4.3 & 15 & 8.1 \\
\hline \multicolumn{7}{|l|}{ Micronutrient statement } \\
\hline Vitamin and mineral supplements increase energy levels ${ }^{\mathrm{b}}$ & 136 & 73.5 & 12 & 6.5 & 37 & 20.0 \\
\hline
\end{tabular}

TABLE 2: Anthropometry, body composition, flexibility, and aerobic and anaerobic power of soccer players by nutritional knowledge.

\begin{tabular}{|c|c|c|c|c|c|}
\hline & Total $(n=185)$ & Low NK $(n=57)$ & Moderate NK $(n=78)$ & High NK $(n=50)$ & Comparison \\
\hline Age (yr) & $21.3 \pm 4.9$ & $19.7 \pm 4.1^{\mathrm{H}}$ & $20.8 \pm 4.2^{\mathrm{H}}$ & $24.1 \pm 5.8^{\mathrm{L}, \mathrm{M}}$ & $F_{2,182}=13.1, p<0.001, \eta^{2}=0.13$ \\
\hline Weight (kg) & $72.3 \pm 8.4$ & $70.1 \pm 8.6^{\mathrm{H}}$ & $72.3 \pm 8.5$ & $74.6 \pm 7.3^{\mathrm{L}}$ & $F_{2,182}=3.9, p=0.021, \eta^{2}=0.04$ \\
\hline Height $(\mathrm{cm})$ & $177.5 \pm 6.4$ & $176.4 \pm 6.3$ & $177.1 \pm 6.5$ & $179.3 \pm 6.3$ & $F_{2,182}=2.8, p=0.062, \eta^{2}=0.03$ \\
\hline $\mathrm{BMI}\left(\mathrm{kg} \cdot \mathrm{m}^{-2}\right)$ & $22.9 \pm 2.0$ & $22.5 \pm 2.2$ & $23.0 \pm 2.1$ & $23.2 \pm 1.6$ & $F_{2,182}=1.7, p=0.182, \eta^{2}=0.02$ \\
\hline $\mathrm{BF}(\%)$ & $14.5 \pm 3.8$ & $14.6 \pm 3.5$ & $14.5 \pm 4.1$ & $14.4 \pm 3.8$ & $F_{2,182}<0.1, p=0.963, \eta^{2}<0.01$ \\
\hline FM (kg) & $10.7 \pm 3.7$ & $10.4 \pm 3.4$ & $10.7 \pm 3.9$ & $10.9 \pm 3.6$ & $F_{2,182}=0.2, p=0.780, \eta^{2}<0.01$ \\
\hline FFM (kg) & $61.6 \pm 6.2$ & $59.7 \pm 6.3^{\mathrm{H}}$ & $61.7 \pm 6.4$ & $63.7 \pm 5.2^{\mathrm{L}}$ & $F_{2,182}=5.7, p=0.004, \eta^{2}=0.06$ \\
\hline $\mathrm{SAR}(\mathrm{cm})$ & $24.5 \pm 7.0$ & $22.6 \pm 7.0$ & $25.2 \pm 6.8$ & $25.6 \pm 7.0$ & $F_{2,181}=3.1, p=0.046, \eta^{2}=0.03$ \\
\hline $\mathrm{PWC}_{170}(\mathrm{~W})$ & $205 \pm 31$ & $201 \pm 42$ & $207 \pm 47$ & $205 \pm 31$ & $F_{2,177}=0.3, p=0.745, \eta^{2}<0.01$ \\
\hline $\mathrm{PWC}_{170}\left(\mathrm{~W} \cdot \mathrm{kg}^{-1}\right)$ & $2.83 \pm 0.48$ & $2.86 \pm 0.49$ & $2.85 \pm 0.53$ & $2.75 \pm 0.39$ & $F_{2,177}=0.8, p=0.439, \eta^{2}=0.01$ \\
\hline$P_{\text {peak }}(\mathrm{W})$ & $816 \pm 122$ & $782 \pm 112^{\mathrm{H}}$ & $825 \pm 129$ & $840 \pm 115^{\mathrm{L}}$ & $F_{2,178}=3.4, p=0.034, \eta^{2}=0.04$ \\
\hline$P_{\text {peak }}\left(\mathrm{W} \cdot \mathrm{kg}^{-1}\right)$ & $11.3 \pm 1.0$ & $11.1 \pm 0.9$ & $11.4 \pm 1.0$ & $11.3 \pm 1.0$ & $F_{2,178}=1.2, p=0.313, \eta^{2}=0.01$ \\
\hline$P_{\text {mean }}(\mathrm{W})$ & $618 \pm 86$ & $597 \pm 88$ & $620 \pm 84$ & $637 \pm 84$ & $F_{2,172}=2.8, p=0.063, \eta^{2}=0.03$ \\
\hline$P_{\text {mean }}\left(\mathrm{W} \cdot \mathrm{kg}^{-1}\right)$ & $8.54 \pm 0.82$ & $8.51 \pm 0.83$ & $8.57 \pm 0.86$ & $8.52 \pm 0.76$ & $F_{2,172}=0.1, p=0.895, \eta^{2}<0.01$ \\
\hline FI (\%) & $45.0 \pm 6.9$ & $44.2 \pm 5.7$ & $45.9 \pm 7.7$ & $44.7 \pm 6.8$ & $F_{2,172}=1.0, p=0.381, \eta^{2}=0.01$ \\
\hline
\end{tabular}

$\mathrm{NK}=$ nutritional knowledge, $\mathrm{BMI}=$ body mass index, $\mathrm{BF}=$ body fat, $\mathrm{FM}=$ fat mass, $\mathrm{FFM}=$ fat free mass, $\mathrm{SAR}=$ sit-and-reach test, $\mathrm{PWC}$ capacity in heart rate $170 \mathrm{bpm}, P_{\text {peak }}=$ peak power, $P_{\text {mean }}=$ mean power, and $\mathrm{FI}=$ fatigue index.

Letters $\mathrm{H}, \mathrm{L}$, and $\mathrm{M}$ when presenting as superscripts denote difference from group with high, low, and moderate nutritional knowledge, respectively.

the question about the necessity of protein supplements was equal with those who answered mistakenly. The majority agreed mistakenly with the sentence that "should not eat sweets prior to an event" and that "protein is the main energy source for the muscle."

Compared with their knowledge on macronutrients, soccer players had better performance in the questions concerning hydration. Particularly, they answered correctly three out of four questions; they agreed correctly that "should replace fluids before, during and after an event" and that "dehydration decreases performance," and disagreed correctly with the sentence that they "should rely on thirst to ensure fluid replacements." In contrast, they disagreed incorrectly with that "sports drinks are better than water".

\section{Discussion}

The main findings were that the overall nutrition knowledge score of the large sample of soccer players participating in this study was evaluated as poor and this score was related to age, weight, height, fat free mass, flexibility, and anaerobic power. The comparison between groups differing in nutrition knowledge revealed differences with regards to body composition and anaerobic power. Particularly, we observed that soccer players with high score in NKQ were heavier $(\sim 4.5 \mathrm{~kg})$ than their counterparts with low score. This difference reflected mainly the higher amount of FFM $(\sim 4 \mathrm{~kg})$ indicating that nutrition knowledge might help soccer players increase their FFM. 
TABLE 3: Pearson correlations of nutritional knowledge with anthropometry, body composition, flexibility, and aerobic and anaerobic power.

\begin{tabular}{lc}
\hline & Pearson $r$ \\
\hline Age $(\mathrm{yr})$ & $0.34^{\ddagger}$ \\
Weight $(\mathrm{kg})$ & $0.21^{\dagger}$ \\
Height $(\mathrm{cm})$ & $0.20^{\dagger}$ \\
BMI $\left(\mathrm{kg} \cdot \mathrm{m}^{-2}\right)$ & 0.11 \\
BF $(\%)$ & -0.02 \\
FM $(\mathrm{kg})$ & 0.05 \\
FFM $(\mathrm{kg})$ & $0.25^{\ddagger}$ \\
SAR $(\mathrm{cm})$ & $0.15^{*}$ \\
PWC & 0.04 \\
PWC & $(\mathrm{W})$ \\
$P_{\text {peak }}(\mathrm{W})$ & -0.09 \\
$P_{\text {peak }}\left(\mathrm{W} \cdot \mathrm{kg}^{-1}\right)$ & $0.18^{*}$ \\
$P_{\text {mean }}(\mathrm{W})$ & 0.04 \\
$P_{\text {mean }}\left(\mathrm{W} \cdot \mathrm{kg}^{-1}\right)$ & $0.20^{\dagger}$ \\
FI $(\%)$ & 0.01 \\
\hline
\end{tabular}

$\mathrm{BMI}=$ body mass index, $\mathrm{BF}=$ body fat, $\mathrm{FM}=$ fat mass, $\mathrm{FFM}=$ fat free mass, $\mathrm{SAR}=$ sit-and-reach test, $\mathrm{PWC}_{170}=$ physical working capacity in heart rate $170 \mathrm{bpm}, P_{\text {peak }}=$ peak power, $P_{\text {mean }}=$ mean power, and FI $=$ fatigue index. ${ }^{*} P<0.05,{ }^{\dagger} P<0.01$ and ${ }^{\ddagger} P<0.001$.

The excess of FFM in the group of high score in NKQ explains partially their increased $P_{\text {peak }}(\sim 59 \mathrm{~W})$ in the WAnT; we observed difference in $P_{\text {peak }}$ expressed as $\mathrm{W}$, but when the values were adjusted for body mass (i.e., $\mathrm{W} \cdot \mathrm{kg}^{-1}$ ) there was no significant difference. An interpretation of these findings might be that good nutrition knowledge results in good dietary choices, which in turn contributed to increased FFM. Thus, considering the close relationship between FFM and muscle power $[18,19]$, it was not surprising to observe high muscle power (in absolute values) in soccer players with high FFM.

However, these findings did not provide insights for the exact mechanisms of this relationship, because nutrition behavior was not measured. A review of studies assessing the relationship between knowledge and dietary intake supported that 5 of 9 studies reported a positive but of moderate magnitude association between these parameters [20]. This conclusion was also confirmed by a more recent review [21]. In addition to cross-sectional studies, the relationship between nutrition knowledge and behavior has been also examined with longitudinal design. Even in the latter case, the findings of previous studies were not always consistent; however, most of them indicated changes in both nutrition knowledge and behavior in the same direction. For instance, NCAA female volleyball players after one year [22] and college female athletes after an 8-week intervention improved both [23], whereas six sessions improved knowledge but not dietary intake in university elite athletes [24].

This is not the first study to observe poor nutrition knowledge in a sport population. Previous research on athletes [25-27] and nonathletes [28] had already shown important nutrition concerns. For instance, poor knowledge of the foods required for refueling, sport drinks, and the role of protein in muscle formation was found in Irish rugby players aged 15$18 \mathrm{yr}$ [27]. In a research on female collegiate swimmers there was lack of knowledge of nutrition [25], whereas in a research on female collegiate cross-country runners it was suggested that these athletes lacked nutrition knowledge critical to preventing nutrition-related health problems [26]. A modest nutrition knowledge and misconception with respect to the sugar content in food or in beverages were recorded in a large sample of adolescents aged 12.5-17.5 yr [28]. Consequently, the findings of this study combined with those of previous research indicated the need for nutrition education of athletes. As the stepwise regression analysis in the present study showed, age was the best predictor of nutrition knowledge (i.e., the older the soccer player, the higher the NKQ score). The role of age was also mentioned by a study on elite Australian athletes [29]. Therefore, educational interventions regarding nutrition should target younger players.

A limitation of this study was that this questionnaire has not been previously validated against other measures of nutrition knowledge. However, the questionnaire has face validity [30], because it covered most of the content it was supposed to measure (e.g., carbohydrates and fats as energy sources and role of proteins, water, minerals, and vitamins) [31]. On the other hand, despite the advancement of research in the field of nutrition since the development of this questionnaire in 2002, our findings revealed its content to be quite timely (e.g., the misconceptions that "protein is the main energy source for the muscle" and "vitamin and mineral supplements increase energy levels"). Moreover, this is the first study to examine the relationship between nutrition knowledge and physical fitness in soccer players and, thus, our findings can be used as a reference for future research on soccer players' nutrition knowledge.

\section{Conclusions}

The moderate score in the NKQ suggests that soccer players should be targeted for nutrition education. Based on our findings, a nutrition intervention should aim to educate soccer players especially with regard to the role of proteins and vitamins, both of which were considered mistakenly by the majority of subjects to increase energy levels. Even if the association between NKQ and physical fitness was low to moderate, there were indications that better nutrition knowledge might result in increased physical fitness and, consequently, soccer performance.

\section{Conflict of Interests}

The authors declare that there is no conflict of interests regarding the publication of this paper.

\section{References}

[1] "Nutrition for football: the FIFA/F-MARC Consensus Conference," Journal of Sports Sciences, vol. 24, no. 7, pp. 663-664, 2006. 
[2] J. Bangsbo, M. Mohr, and P. Krustrup, "Physical and metabolic demands of training and match-play in the elite football player," Journal of Sports Sciences, vol. 24, no. 7, pp. 665-674, 2006.

[3] L. M. Burke, A. B. Loucks, and N. Broad, "Energy and carbohydrate for training and recovery," Journal of Sports Sciences, vol. 24, no. 7, pp. 675-685, 2006.

[4] K. Clark, "Nutritional guidance to soccer players for training and competition," Journal of Sports Sciences, vol. 12, pp. S43-S50, 1994.

[5] M. Hargreaves, "Carbohydrate and lipid requirements of soccer," Journal of Sports Sciences, vol. 12, pp. S13-S16, 1994.

[6] O. Bar-Or and V. B. Unnithan, "Nutritional requirements of young soccer players," Journal of Sports Sciences, vol. 12, pp. S39S42, 1994.

[7] S. M. Shirreffs, "Hydration: special issues for playing football in warm and hot environments," Scandinavian Journal of Medicine \& Science in Sports, vol. 20, supplement 3, pp. 90-94, 2010.

[8] C. M. Reñón and P. S. Collado, "Nutritional study of a third division soccer team," Nutricion Hospitalaria, vol. 28, no. 2, pp. 319-324, 2013.

[9] G. Garrido, A. L. Webster, and M. Chamorro, "Nutritional adequacy of different menu settings in elite Spanish adolescent soccer players," International Journal of Sport Nutrition and Exercise Metabolism, vol. 17, no. 5, pp. 421-432, 2007.

[10] F. Ruiz, A. Irazusta, S. Gil, J. Irazusta, L. Casis, and J. Gil, "Nutritional intake is soccer players of different ages," Journal of Sports Sciences, vol. 23, no. 3, pp. 235-242, 2005.

[11] J. C. Leblanc, F. Le Gall, V. Grandjean, and P. Verger, "Nutritional intake of French soccer players at the Clairefontaine training center," International Journal of Sport Nutrition and Exercise Metabolism, vol. 12, no. 3, pp. 268-280, 2002.

[12] C. A. Rosenbloom, S. S. Jonnalagadda, and R. Skinner, "Nutrition knowledge of collegiate athletes in a division I National Collegiate Athletic Association Institution," Journal of the American Dietetic Association, vol. 102, no. 3, pp. 418-420, 2002.

[13] J. Parizkova, Body Fat and Physical Fitness, Martinus Nijhoff, The Hague, The Netherlands, 1977.

[14] F. Ayala, P. Sainz de Baranda, M. De Ste Croix, and F. Santonja, "Reproducibility and criterion-related validity of the sit and reach test and toe touch test for estimating hamstring flexibility in recreationally active young adults," Physical Therapy in Sport, vol. 13, no. 4, pp. 219-226, 2012.

[15] J. Bland, K. Pfeiffer, and J. C. Eisenmann, "The PWC170: comparison of diVerent stage lengths in 11-16 year olds," European Journal of Applied Physiology, vol. 112, no. 5, pp. 1955-1961, 2012.

[16] T. Driss and H. Vandewalle, "The measurement of maximal (anaerobic) power output on a cycle ergome ter: a critical review," BioMed Research International, vol. 2013, Article ID 589361, 40 pages, 2013.

[17] J. Cohen, Statistical Power Analysis for the Behavioral Sciences, Lawrence Erlbaum Associates, Hillsdale, NJ, USA, 1988.

[18] P. T. Nikolaidis, "Age-related differences in countermovement vertical jump in soccer players 8-31 years old: the role of fat free mass," American Journal of Sports Science and Medicine, vol. 2, no. 2, pp. 60-64, 2014.

[19] C. Aouichaoui, Y. Trabelsi, E. Bouhlel et al., "The relative contributions of anthropometric variables to vertical jumping ability and leg power in Tunisian children," Journal of Strength and Conditioning Research, vol. 26, no. 3, pp. 777-788, 2012.

[20] S. Heaney, H. O'Connor, S. Michael, J. Gifford, and G. Naughton, "Nutrition knowledge in athletes: a systematic review," International Journal of Sport Nutrition and Exercise Metabolism, vol. 21, no. 3, pp. 248-261, 2011.

[21] I. Spronk, C. Kullen, C. Burdon, and H. O'Connor, "Relationship between nutrition knowledge and dietary intake," British Journal of Nutrition, vol. 111, no. 10, pp. 1713-176, 2014.

[22] M. W. Valliant, H. Pittman, R. K. Wenzel, and B. H. Garner, "Nutrition education by a registered dietitian improves dietary intake and nutrition knowledge of a NCAA female volleyball team," Nutrients, vol. 4, no. 6, pp. 506-516, 2012.

[23] D. A. Abood, D. R. Black, and R. D. Birnbaum, "Nutrition education intervention for college female athletes," Journal of Nutrition Education and Behavior, vol. 36, no. 3, pp. 135-139, 2004.

[24] L. Martinelli, "The implementation and evaluation of a nutrition education programme for university elite athletes," Progress in Nutrition, vol. 15, no. 2, pp. 71-80, 2013.

[25] B. J. Hoogenboom, J. Morris, C. Morris, and K. Schaefer, "Nutritional knowledge and eating behaviors of female, collegiate swimmers," North American Journal of Sports Physical Therapy, vol. 4, no. 3, pp. 139-148, 2009.

[26] L. G. Zawila, C. M. Steib, and B. Hoogenboom, "The female collegiate cross-country runner: nutritional knowledge and attitudes," Journal of Athletic Training, vol. 38, no. 1, pp. 67-74, 2003.

[27] M. Walsh, L. Cartwright, C. Corish, S. Sugrue, and R. WoodMartin, "The body composition, nutritional knowledge, attitudes, behaviors, and future education needs of senior schoolboy rugby players in Ireland," International Journal of Sport Nutrition and Exercise Metabolism, vol. 21, no. 5, pp. 365-376, 2011.

[28] W. Sichert-Hellert, L. Beghin, S. de Henauw et al., "Nutritional knowledge in European adolescents: results from the HELENA (Healthy Lifestyle in Europe by Nutrition in Adolescence) study," Public Health Nutrition, vol. 14, no. 12, pp. 2083-2091, 2011.

[29] J. K. Spendlove, S. E. Heaney, J. A. Gifford, T. Prvan, G. S. Denyer, and H. T. O'Connor, "Evaluation of general nutrition knowledge in elite Australian athletes," The British Journal of Nutrition, vol. 107, no. 12, pp. 1871-1880, 2012.

[30] F. J. Gravetter and L. A. B. Forzano, Research Methods for the Behavioral Sciences, Wadsworth, Belmont, Mass, USA, 4th edition, 2012.

[31] L. Burke and V. Deakin, Clinical Sports Nutrition, McGraw-Hill, North Ryde, Australia, 4th edition, 2010. 


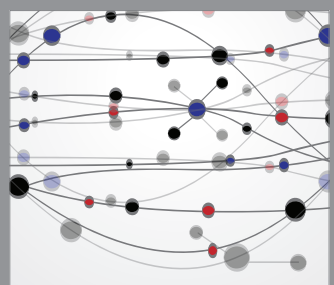

The Scientific World Journal
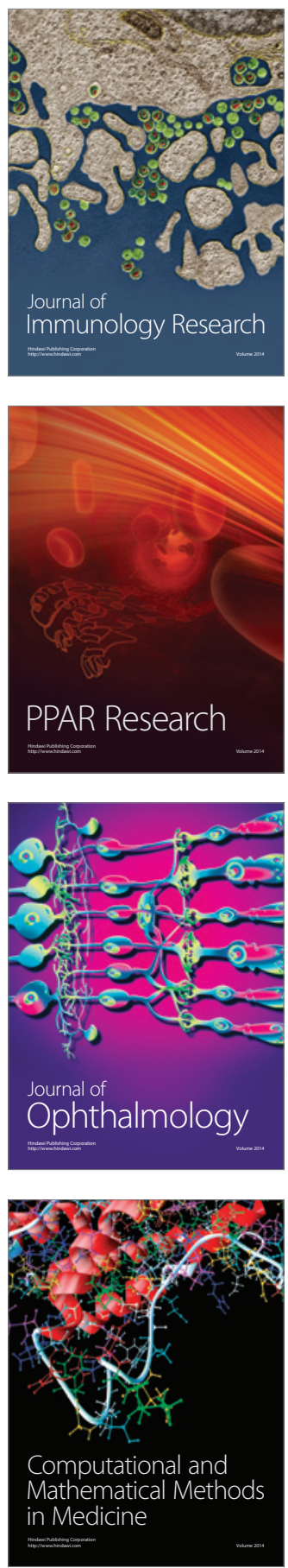

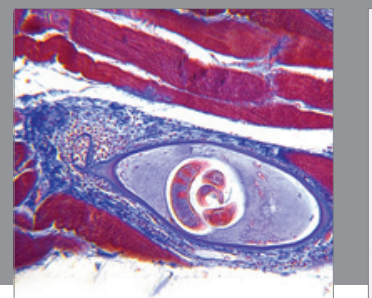

Gastroenterology

Research and Practice
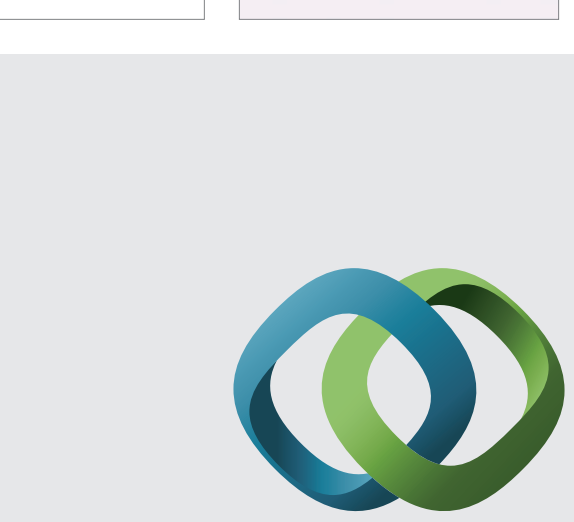

\section{Hindawi}

Submit your manuscripts at

http://www.hindawi.com
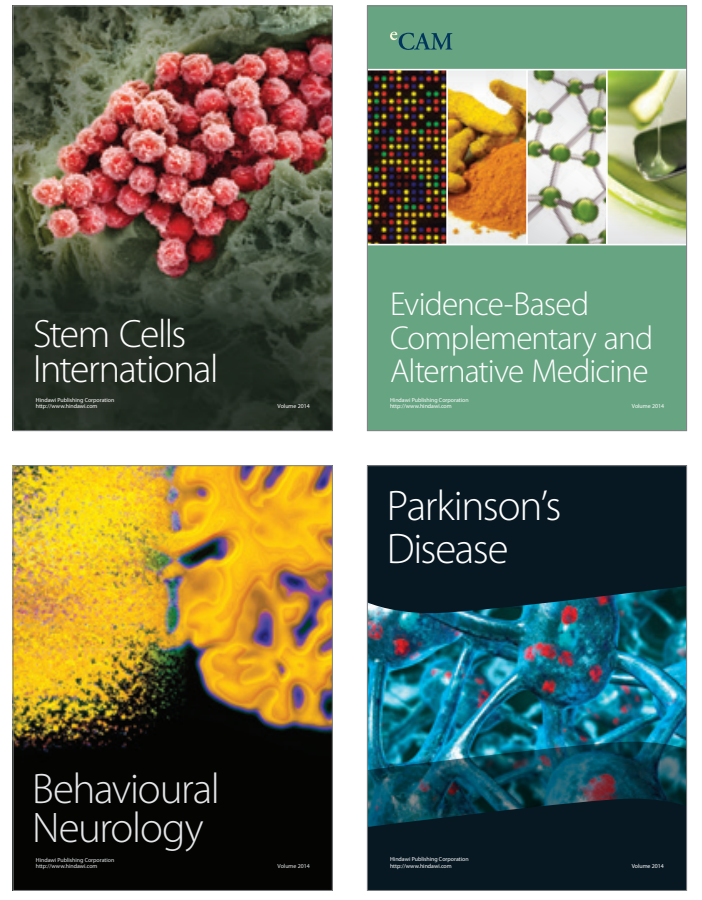
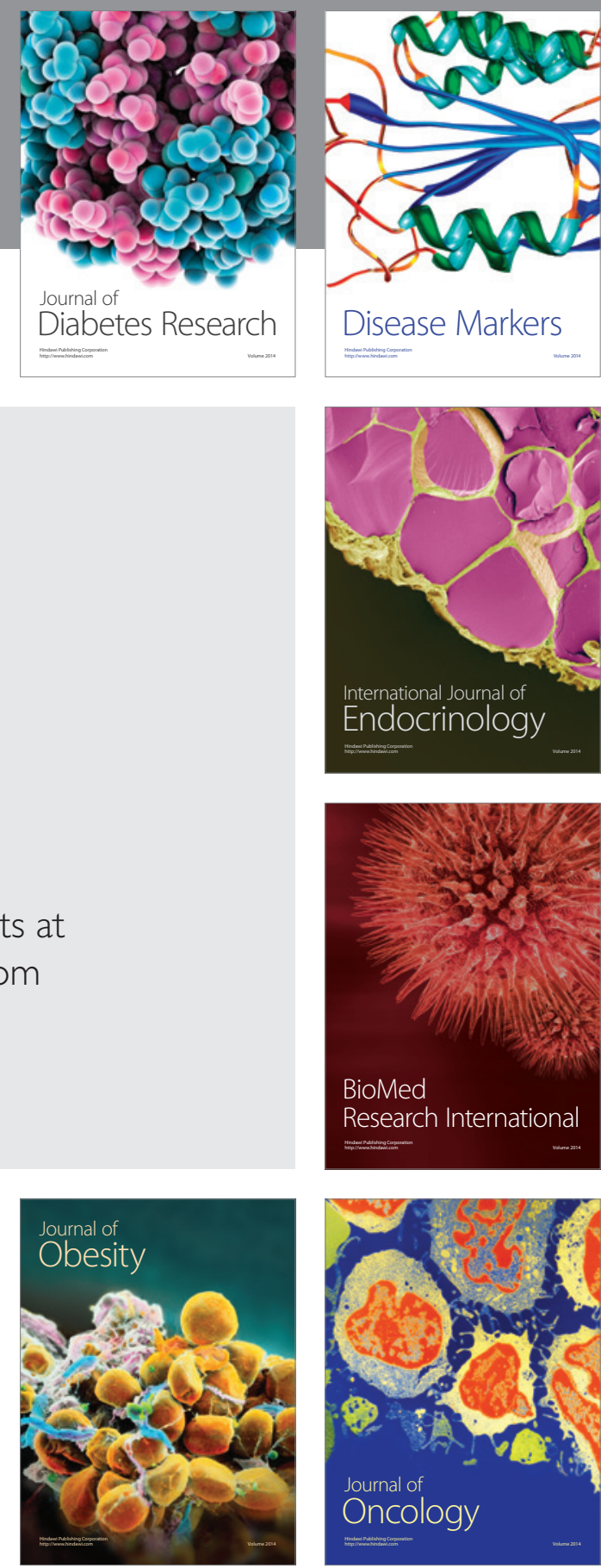

Disease Markers
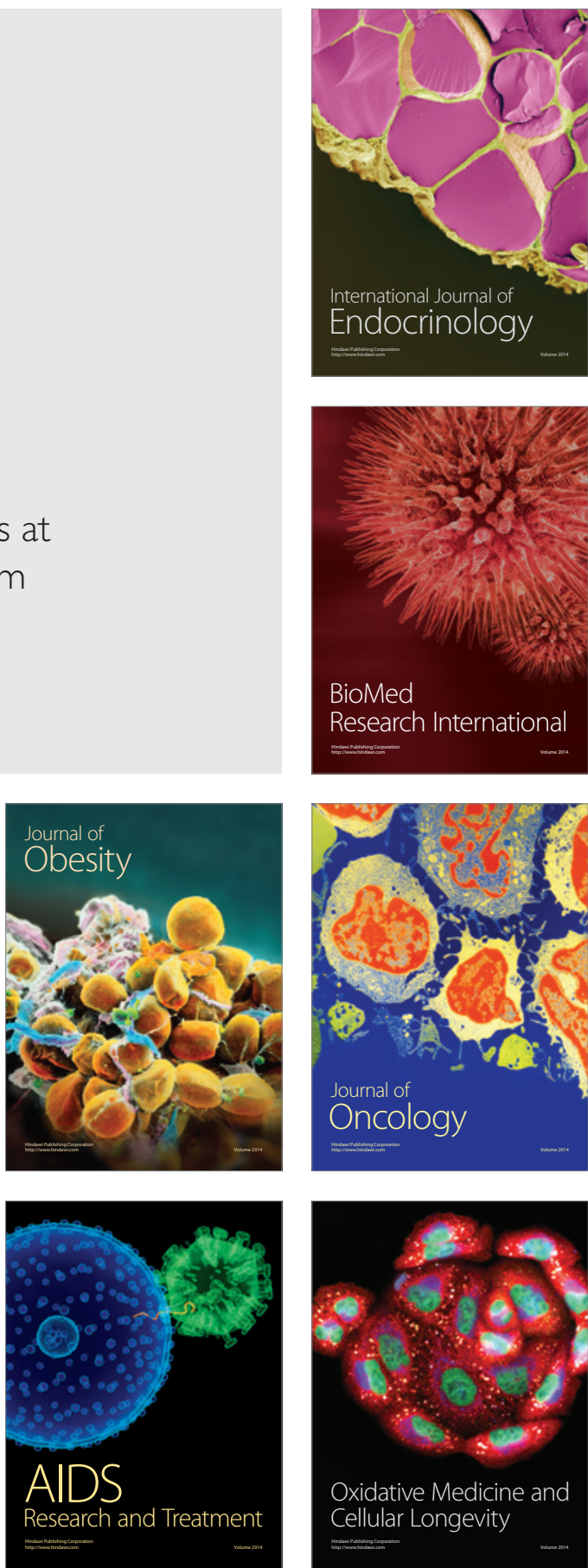